\title{
FORMACIÓN SUPERIOR BASADA EN COMPETENCIAS, INTERDISCIPLINARIEDAD Y TRABAJO AUTÓNOMO DEL ESTUDIANTE
}

\author{
Rodolfo Posada Álvarez \\ Facultad de Educación, Universidad del Atlántico, Colombia
}

\section{COMPETENCIA Y DESEMPEÑO}

El concepto de competencia es diverso, según el ángulo del cual se mire o el énfasis que se le otorgue a uno u otro elemento, pero el más generalizado y aceptado es el de "saber hacer en un contexto". El "saber hacer", lejos de entenderse como "hacer" a secas, requiere de conocimiento (teórico, práctico o teórico-práctico), afectividad, compromiso, cooperación y cumplimiento, todo lo cual se expresa en el desempeño, también de tipo teórico, práctico o teórico-práctico. Por ejemplo, cuando alguien lee un texto y lo interpreta (saber hacer) ejecuta una acción (desempeño) en un contexto teórico (contenido del texto). Cuando un mecánico empírico arregla un vehículo (desempeño) aplica un conocimiento práctico en un contexto (situación y condiciones en que se da el desempeño) igualmente práctico.

Según Sladogna1, las competencias son capacidades complejas que poseen distintos grados de integración y se manifiestan en una gran variedad de situaciones en los diversos ámbitos de la vida humana personal y social. Son expresiones de los diferentes grados de desarrollo personal y de participación activa en los procesos sociales. Agrega la autora que toda competencia es una síntesis de las experiencias que el sujeto ha logrado construir en el marco de su entorno vital amplio, pasado y presente. Masseilot ${ }^{2}$ afirma que el concepto de competencia es elástico y flexible, dirigido a superar la brecha entre trabajo intelectual y manual.

Como puede verse, el concepto de competencia es bastante amplio, integra conocimientos, potencialidades, habilidades, destrezas, prácticas y acciones de diversa índole (personales, colectivas, afectivas, sociales, culturales) en los diferentes escenarios de aprendizaje y desempeño.

Las competencias se expresan en su forma más expedita en el desempeño. Maurino y colaboradores $^{3}$ proponen una taxonomía que comprende tres niveles de desempeño humano basado en:

- Habilidades en tareas ampliamente practicadas y programadas

- Reglas preestablecidas en una situación modificada y prevista

\footnotetext{
${ }^{1}$ SLADOGNA, Mónica G. "Una mirada a la construcción de las competencias desde el sistema educativo. La experiencia Argentina". En: CINTERFOR-OIT. Competencias laborales en la formación profesional. Boletín Técnico Interamericano de Formación Profesional. $\mathrm{N}^{\circ} 149$, mayo-agosto de 2000, p. 115.

2 MASSEILOT, Héctor. "Competencias laborales y procesos de certificación ocupacional". En: CINTERFOR-OIT. Competencias laborales en la formación profesional. Boletín Técnico Interamericano de Formación Profesional. № 149, mayo-agosto de 2000 , p. 79.

${ }^{3}$ MAURINO, D.E., et al. Beyond aviation: Human factors. Avebury: Aldershot, 1995. En: CAPPER, Phillip. "La competencia en contextos laborales complejos". En: ARGÜELLES, Antonio y GONCZI, Andrew. Educación y capacitación basada en normas de competencias: una perspectiva internacional. México: Limusa, 2001, p. 200.
} 
- Conocimiento (comprensión) y uso de técnicas para la resolución de problemas y para encontrar soluciones a situaciones nuevas.

Sostiene Capper ${ }^{4}$ que las concepciones tradicionales sobre los 3 tópicos anteriores han resultado tenaces. Considerando que el conocimiento y la habilidad son los máximos depositarios del poder y el estatus, se infiere que la interpretación más ancestral sobre la habilidad le otorga una relativa estabilidad social y laboral a quienes detentan el poder, por lo que tienen interés en mantener esa concepción. Por lo tanto, tal como se concibe la adquisición de habilidades y pericias (conocimientos y habilidades adquiridas por peritos) en el modelo tradicional es profundamente conservadora y contribuye poco al logro de altos niveles de desempeño e innovación.

Estudios empíricos recientes muestran que los "expertos" no siempre dan muestras de un excelente desempeño, mientras que por lo general los "novatos" lo hacen mejor ${ }^{5}$. La complejidad también desafía los modelos individualistas y tradicionales relacionados con la pericia. Por ejemplo, el manejo y análisis en equipo de la información es más importante que llevarlos a cabo individualmente ${ }^{6}$. Así mismo, la acción colectiva es más trascendental y vigorosa que la contribución particular de cualquier persona. En este sentido, la pericia es un producto de la participación en un sistema de actividades tanto como del esfuerzo individual. En tales circunstancias, anota Capper $^{7}$, comportarse como un actor individual competente es un acto incompetente.

De acuerdo con Capper $^{8}$, los conceptos predominantes actualmente en materia de competencias laborales son erróneos porque se fundamentan en:

- La adquisición individual de habilidades técnicas, sin considerar las organizacionales y el trabajo en equipo, indispensables para la producción autoadministrada, la constitución de equipos multifuncionales, la cultura empresarial, la estructura, los sistemas operativos y los procesos de producción que caracterizan a las organizaciones de vanguardia.

- La educación y capacitación formales sin tener en cuenta el aprendizaje cotidiano producto del trabajo, clave para la optimización del aprendizaje y el perfeccionamiento continuo.

- Los niveles de habilidad de los empleados nuevos o sin trabajo, sin considerar los conocimientos, valores y habilidades que requieren los gerentes, los supervisores y demás personal responsable de facilitar el aprendizaje continuo.

- Desde esta perspectiva se requiere, entonces, redefinir las habilidades y competencias, teniendo en cuenta las condiciones de incertidumbre y considerando los siguientes hechos ${ }^{9}$ :

\footnotetext{
${ }^{4}$ CAPPER, Phillip. "La competencia en contextos laborales complejos”. En: ARGÜELLES y GONCZI, op. cit., p. 201.

${ }^{5}$ CAPPER, op. cit. p. 203.

${ }^{6}$ BERLO, D. K. The context for comunication. Cit. En: CAPPER, Ibid.

${ }^{7}$ CAPPER, op. cit. p. 207.

${ }^{8}$ Ibid, p. 212-213
} 
- Cada día se oye hablar más de habilidades "duras" y "blandas", se distinguen las habilidades psicomotrices y cognitivas observables -que dominaron en el pasado- de los procesos y habilidades cognitivas y afectivas, que hoy están adquiriendo mayor importancia.

- Las habilidades técnicas "duras" son cada vez más efímeras, mientras que las habilidades de proceso, pese a que son llamadas "blandas", se están convirtiendo en un requisito indispensable en la mayoría de los empleos. De hecho, no son en absoluto habilidades "blandas". Actualmente existe una tendencia a asignarle una "vida útil" a las habilidades "duras", pues se admite que éstas se vuelven obsoletas en un determinado lapso. Por ejemplo, la vida útil de las habilidades de un ingeniero de programación es de aproximadamente dos años, como lo ha observado Leo Burke, de la Universidad Motorola.

- El desempeño basado en habilidades y/o reglas puede ser individual, según el nivel de pericia personal, pero en determinados casos requiere colaboración (trabajo en equipo) debido a la complejidad o exigencias físicas propias de una tarea.

- El desempeño basado en el conocimiento sólo puede optimizarse mediante discusiones críticas y conversaciones colectivas con espíritu de colaboración.

- Las propias industrias del aprendizaje y la investigación están inmersas en la incertidumbre. Así mismo, las respuestas "correctas y universales" a preguntas de índole organizacional y administrativa deben considerarse con escepticismo.

Por otra parte, la manera como fluye la información ha cambiado radicalmente, pues el desarrollo de tecnologías informáticas individualizadas, móviles y en redes, ha logrado que la comunicación fluya de "muchos a muchos" en ves de "uno a muchos"10. En consecuencia, las personas se ven cada vez más enfrentadas a ráfagas de información y a encontrarle significado a ésta. Dicha información ya es suministrada a la gente personalmente y/o se tiene la posibilidad de adquirirla y administrarla por iniciativa propia.

Dice Capper ${ }^{11}$ que los nuevos enfoques sobre competencia, desempeño, habilidad, pericia, conocimiento, etc., implican transformar las organizaciones: especialización flexible, orientación hacia el cliente, darle poder a la gente, administración horizontal, autoadministración, equipos autodirigidos y aprendizaje continuo, pasar de relaciones experto-novato a unas basadas en discusiones críticas en las cuales es probable que el "novato" sea capaz de hacer aportes valiosos al "experto".

\footnotetext{
${ }^{9}$ Ibid, p. 208-211

${ }^{10}$ Ibid, p. 203

${ }^{11} \mathrm{Ibid}$, p. 208
} 


\section{COMPETENCIAS LABORALES}

No existe un único concepto, tampoco un consenso, sobre la definición de competencia laboral, pero, según Vargas ${ }^{12}$, si existen elementos comunes en las diferentes definiciones que permiten inferir unas características esenciales de la competencia laboral: a) está orientada al desempeño en el trabajo, en situaciones definidas, c) usualmente se contrasta ante un patrón o norma de desempeño esperado, d) incluye un gran acervo de capacidades personales y sociales, sobre todo las de trabajar en equipo y establecer relaciones.

La Organización Internacional del Trabajo (OIT) ${ }^{13}$ asume el concepto de competencia laboral como la idoneidad para realizar una tarea o desempeñar un puesto de trabajo eficazmente, con las requeridas certificaciones para ello. En este caso, competencia y calificación laboral se asocian fuertemente dado que esta última certifica una capacidad adquirida para realizar o desempeñar un trabajo.

En España, el Instituido Nacional para el Empleo (INEM) ${ }^{14}$ sostiene que en las competencias laborales se concreta el ejercicio eficaz de las capacidades para el desempeño en una ocupación. Son algo más que el conocimiento técnico referido al mero "saber hacer". Desde esta perspectiva, el concepto de competencia abarca no sólo las capacidades necesarias para el pleno ejercicio de una ocupación o profesión, sino también un conjunto de comportamientos, facultades para el análisis, toma de decisiones, transmisión de información, etc.

En Australia ${ }^{15}$ la competencia laboral se concibe como un conjunto de características necesarias para el desempeño en contextos específicos. Es una compleja combinación de condiciones (conocimiento, actitudes, valores, habilidades) y tareas a desempeñar en determinadas situaciones. Este ha sido considerado un enfoque holístico en la medida que integra y relaciona atributos y tareas, permite que ocurran varias acciones intencionales simultáneamente y toma en cuenta el contexto y la cultura del lugar de trabajo. Permite incorporar la ética y los valores como elementos del desempeño competente.

En Alemania $^{16}$ posee competencia laboral quien dispone de los conocimientos, destrezas y aptitudes necesarios para ejercer una profesión u ocupación, resolver los problemas profesionales en forma autónoma y flexible, colaborar en su entorno de trabajo y en la organización en donde se desempeña.

En Inglaterra ${ }^{17}$, más que encontrar una definición de competencia laboral, el concepto subyace en la estructura del sistema laboral normatizado. Este tipo de competencia se identifica en las normas a través de

\footnotetext{
${ }^{12}$ VARGAS ZÚÑIGA, Fernando. "De las virtudes laborales a las competencias claves: un nuevo concepto para antiguas demandas". En: CINTERFOR-OIT. Competencias laborales en la formación profesional. Boletín Técnico Interamericano de Formación Profesional. $\mathrm{N}^{\circ}$ 149, mayo-agosto de 2000, p. 21.

${ }_{13}$ ORGANIZACIÓN INTERNACIONAL DEL TRABAJO. Formación profesional. Glosario de términos escogidos. Ginebra, 1993.

${ }^{14}$ INSTITUTO NACIONAL PARA EL EMPLEO. Metodología para la ordenación de la formación profesional ocupacional. Subdirección General de Gestión de Formación Ocupacional. Madrid, 1995.

${ }^{15}$ GONCZI, Andrew y ATHANASOU, James. Instrumentación de la educación basada en competencias. Perspectiva de la teoría y la práctica en Australia. Limusa, 1996.

${ }^{16}$ BUNK, G. P. La transmisión de las competencias en la formación y perfeccionamiento profesionales en la RFA. Revista CEDEFOP, № 1, 1994.

${ }^{17}$ CONSEJO NACIONAL DE CERTIFICACIÓN. www.cinterfor.org.uy
} 
elementos de competencia (logros laborales que un trabajador es capaz de conseguir), criterios de desempeño (definiciones acerca de la calidad), el campo de aplicación y los conocimientos requeridos. En el sistema inglés se han definido cinco niveles de competencia laboral, que permiten diferenciar el grado de autonomía, la variabilidad, la responsabilidad por recursos, la aplicación de conocimientos básicos, la amplitud y alcance de las habilidades y destrezas, la supervisión del trabajo y la transferencia de un ámbito laboral a otro. Dichos niveles son:

- $\quad$ Nivel 1: Competencia en la realización de una variada gama de actividades laborales, en su mayoría rutinarias y predecibles.

- $\quad$ Nivel 2: Competencia en una importante y variada gama de actividades laborales, llevadas a cabo en diferentes contextos. Algunas de dichas actividades son complejas o no rutinarias y existe cierta autonomía y responsabilidad individual. A menudo, puede requerirse la colaboración de otras personas, quizás formando parte de un grupo o equipo de trabajo.

- $\quad$ Nivel 3: Competencia en una amplia gama de diferentes actividades laborales llevadas a cabo en una gran variedad de contextos que, en su mayor parte, son complejos y no rutinarios. Existe una considerable responsabilidad y autonomía y, a menudo, se requiere el control y la provisión de orientación a otras personas.

- Nivel 4: Competencia en una amplia gama de actividades laborales profesionales 0 técnicamente complejas llevadas acabo en una gran variedad de contextos y con un grado considerable de autonomía y responsabilidad personal. A menudo, requiere responsabilizarse por el trabajo de otros y la distribución de recursos.

- Nivel 5: Competencia que implica la aplicación de una importante gama de principios fundamentales y de técnicas complejas en una amplia y a veces impredecible variedad de contextos. Se requiere una autonomía personal muy importante $y$, con frecuencia, gran responsabilidad respecto al trabajo de otros y a la distribución de recursos importantes. Asimismo, exige responsabilidad personal en materia de análisis y diagnósticos, diseño, planificación, ejecución y evaluación.

Comenta $\operatorname{Vargas}^{18}$ que la sola capacidad de llevar a la práctica instrucciones no define la competencia laboral, pues se necesita además la "actuación", es decir, el valor agregado que el individuo competente coloca en juego y que le permite saber encadenar unas instrucciones, no solo aplicarlas aisladamente. Agrega este autor que en una concepción dinámica, las competencias se adquieren a través de la educación, la experiencia y la vida cotidiana, se movilizan de un contexto a otro, se desarrollan continuamente y no pueden explicarse y demostrarse independientemente de un contexto. En esta concepción, la competencia la posee el individuo, es parte de su acervo y su capital intelectual y humano. Es el trabajador o profesional quien posee y moviliza sus recursos de competencia para llevar a cabo con éxito una actividad, tarea u operación. Por tanto, las competencias individuales, grupales y organizacionales 
se convierten en un poderoso motor del aprendizaje y en un aspecto fundamental en la gestión del recurso humano.

Es innegable, entonces, que en torno a las competencias puede impartirse una formación integral. Al respecto dice Gonczy ${ }^{19}$ que el desarrollo de una competencia es una actividad cognitiva compleja que exige a la persona establecer relaciones entre la práctica y la teoría, transferir el aprendizaje a diferentes situaciones, aprender a aprender, plantear y resolver problemas y actuar de manera inteligente y crítica en una situación.

Stevenson ${ }^{20}$ complementa esta posición al sostener que el reto que debe trazarse la sociedad es formar personas capaces de adquirir y poner en práctica habilidades técnicas comercializables y demostrar un comportamiento ético basado en principios. Además, los estudiantes deben adquirir una visión general del mundo que los ayude a entender la necesidad de una acción "prudente y basada en principios", y actuar en consecuencia cada vez que sea necesario.

El ritmo acelerado que vive el mundo en estos tiempos exige a los sistemas educativos retos de enorme importancia. Al respecto anota Robinson y Misko ${ }^{21}$ que algunas de las habilidades técnicas básicas que necesitaremos dentro de 20 años aún no existen. De allí, según dichos autores, la imperiosa necesidad de que, durante el nuevo milenio, los trabajadores requieran cada vez más:

- Excelentes habilidades en materia de relaciones interpersonales y humanas, con el fin de obtener lo mejor de la gente y desempeñarse bien en situaciones de trabajo en equipo

- Habilidades analíticas fundamentales para manejar la enorme cantidad de información disponible actualmente e interpretarla adecuadamente.

- Poseer espíritu empresarial, independientemente de si se dirige una empresa o se trabaja como empleado para otra persona, a fin de estar en capacidad de buscar nuevas oportunidades empresariales en todo momento.

\section{COMPETENCIAS COMUNICATIVAS}

La comunicación es parte esencial del desarrollo humano y social. En esta dirección, las competencias comunicativas son indispensables en los individuos y la sociedad, sobre todo cuando vivimos en un mundo repleto de diversa y múltiple información que circula a través de los diversos medios. Requerimos de información para comprender lo que acontece, pero a la vez necesitamos comprender la información para tomar decisiones.

\footnotetext{
${ }^{18}$ VARGAS ZÚÑIGA, Fernando. Competencia en la formación y competencia en la gestión del talento humano. Convergencias y desafíos. CINTERFOR/OIT, www.cinterfor.org.uy , 2002.

${ }_{19}$ GONCZI, Andrew. "Análisis de las tendencias internacionales y de los avances en educación y capacitación laboral basadas en normas de competencias". En: ARGÜELLES, Antonio y GONCZI, Andrew. Educación y capacitación basada en normas de competencias: una perspectiva internacional. México: Limusa, 2001, p. 38-40.

${ }^{20}$ STEVENSON J. "The political colonization of the cognitive construction of competence". En: MISKO, Josie y ROBINSON, Chris. La capacitación basada en normas de competencia en Australia. En: ARGÜELLES y GONCZI, op. cit. p. 107.
} 
En educación, la comprensión es imprescindible en el aprendizaje y el desempeño. Es ineludible, entonces, comprender la comprensión, preguntarse: ¿Qué es la comprensión? Tina Blythe y colaboradores $^{22}$ responden esta pregunta teniendo en cuenta el desempeño: la comprensión es la capacidad de hacer con algo una variedad de cosas que requieren habilidades de pensamiento (explicar, demostrar, dar ejemplos, generalizar, establecer analogías, etc.), para volver a presentar ese algo de una manera ampliada, nueva, innovadora, propositiva.

La comprensión, como una macrocompetencia, requiere de las competencias comunicativas, entendidas en su más amplio sentido como las capacidades del hablante para establecer relaciones socioculturales e interactuar con su medio ${ }^{23}$. Las siguientes son las competencias comunicativas asumidas por el ICFES para evaluar a los bachilleres colombianos (Pruebas de Estado) y a los estudiantes de últimos semestres de las diferentes profesiones (Exámenes de Calidad de la Educación Superior, ECAES), pero que también son requeridas por el Ministerio de Educación para la formación y el desempeño profesional (Estándares o condiciones mínimas de calidad):

\subsection{Competencia interpretativa}

Interpretar implica: dialogar, relacionar y confrontar significados, con el fin de encontrarle sentido a un texto, una proposición, un problema, gráfico, mapa o esquema, plantear argumentos en pro o en contra de una teoría o propuesta, justificar una afirmación, explicar los por qué de una proposición, demostrar la articulación de conceptos, teorías o partes de un texto que fundamenten la reconstrucción global del mismo, organizar premisas y relaciones causales para sustentar una conclusión, etc. ${ }^{24}$.

\subsection{Competencia argumentativa}

Argumentar es profundizar, asumiendo un punto de vista coherente y riguroso ante una temática o problemática, a través de conceptualizaciones, procedimientos y actitudes. Conlleva una dimensión ética importante al constituirse en una invitación a la participación del otro, caracterizada por el respeto y la tolerancia mutua ${ }^{25}$. La argumentación demanda de los siguientes elementos ${ }^{26}$ : a) Exposición de la o las tesis: presentarla(s) claramente, en favor o en contra. b) Presentación de argumentos: compuestos por una afirmación o conclusión y unas premisas o razones que los sustentan, relacionados con la tesis planteada. c) Plan argumentativo: organización coherente siguiendo un plan o eje argumental. d) Consistencia en los términos: los conceptos básicos empleados no deben resultar contradictorios o confusos. e) Adecuación al auditorio: anticipar el tipo de interlocutor, lo que supone seleccionar el léxico, las demostraciones y los modos de argumentar. f) Nexos argumentales: existencia de vínculos explícitos entre los diferentes argumentos.

\footnotetext{
${ }^{21}$ ROBINSON y MISKO, op. cit. p. 110-111.

22 BLYTHE, Tina, et al. La enseñanza para la comprensión. Buenos Aires: Paidós, 1999, p. 38

${ }^{23}$ HERNÁNDEZ, Carlos Augusto, et al. Exámenes de Estado: una propuesta de evaluación por competencias. Bogotá: Javegraf, 1998, p. 30.

${ }_{24}$ Ibid, p. 37.

${ }^{25}$ Ibid, p. 41.

${ }^{26}$ PÉREZ ABRIL; Mauricio. "Competencia textual, competencia pragmática y competencia argumentativa. Ejes de la evaluación de producción de textos". En: Evaluación de Competencias básicas. Bogotá: Universidad Nacional, 1999, p. 67.
} 


\subsection{Competencia propositiva}

Proponer implica asumir una postura constructiva y creativa, plantear opciones o alternativas ante la problemática presente en un texto o situación determinada ${ }^{27}$. Son acciones propositivas, entre otras: resolver problemas, elaborar hipótesis y argumentos, construir mundos posibles, regularidades, explicaciones y generalizaciones, presentar alternativas ante la confrontación de perspectivas, la solución de conflictos sociales.

Las competencias comunicativas son inherentes al ser humano, pero las personas las poseen en diferentes niveles de desarrollo y complejidad. El "Pibe" Valderrama es un excelente futbolista, pero cuando lo entrevistan, casi siempre responde: "todo bien, todo bien", expresión muy reconocida en Colombia. Pedirle a este eminente deportista que arengue a sus seguidores con discursos, solicitándole al Ministerio de Educación que dote a todas las organizaciones escolares con canchas de fútbol sería un exabrupto. En este caso, acorde con la teoría de Gardner $^{28}$ sobre las inteligencias múltiples, podría decirse que se encuentra muy desarrollada la inteligencia cinético-corporal, más que la inteligencia lingüística.

Gardner asocia la inteligencia con las competencias ejercidas en un contexto. Al respecto considera que "una inteligencia implica la habilidad necesaria para resolver problemas o para elaborar productos que son de importancia en un contexto cultural o en una comunidad determinadas. La capacidad para resolver problemas permite abordar una situación en la cual se persigue un objetivo, así como determinar el camino adecuado que conduce a dicho objetivo"29

\section{ENSEÑANZA Y APRENDIZAJE DE COMPETENCIAS}

La historia de la Educación Basada en Normas de Competencias (EBNC) se remonta a los años treinta del siglo XX en los Estados Unidos ${ }^{30}$. Sin embargo, su manifestación más reciente data de más de 15 años, como un interés más económico que educativo, con el fin de adecuar la educación y capacitación vocacionales a las necesidades de la industria. Desde entonces la EBNC ha sido un concepto muy controvertido entre representantes de los sectores industriales, gubernamentales y educativos, pero también ha generado consenso en torno a que es un buen punto de partida para elevar los niveles de competencias en un determinado país, para aumentar los recursos que se invierten en programas de capacitación y para hacer posible que otras instituciones no gubernamentales impartan capacitación ${ }^{31}$.

Anota Gonczi ${ }^{32}$ que el sistema de competencias hizo posible, por primera vez, que a los estudiantes se les reconocieran sus calificaciones sobre la base de lo que podían demostrar cuando estuvieran listos

\footnotetext{
${ }^{27}$ HERNÁNDEZ, op. cit. p.45.

${ }^{28}$ GARDNER, Howard. Inteligencias múltiples. Barcelona: Paidós, 1995. En esta obra, el autor plantea siete tipos de inteligencia: musical, cinético-corporal, lógico-matemática, lingüística, espacial, interpersonal e intrapersonal (p. 34-42). Dice Gardner que "excepto en el caso de individuos anormales, las inteligencias trabajan siempre en concierto, y que cualquier papel adulto mínimamente complejo implica la mezcla de cada una de ellas". p. 34.

${ }^{29}$ GARDNER, op. cit. p. 33.

${ }^{30}$ HARRIS, R, et al. Competency-based education: Between a rock and whirlpool. McMillan: Melbourne. En: GONCZI, op. cit. En: ARGÜELLES y GONCZI, op. cit. p. 22.

${ }^{31}$ GONCZI, Andrew. "Análisis de las tendencias internacionales y de los avances en educación y capacitación basadas en normas de competencias". En: ARGÜELLES y GONCZI, op. cit. p.19.

${ }^{32}$ GONCZI, op. cit. p.24.
} 
para hacerlo, a diferencia de las modalidades de educación tradicional basadas en las horas de instrucción recibidas.

Gonczi $^{33}$ realizó un estudio sobre el sistema de EBNC en varios países (Australia, Inglaterra, Escocia, Nueva Zelanda, Alemania, Estados Unidos y Canadá), cuya síntesis presentamos:

- En todos los países que han adoptado el sistema, éste se ha establecido para asegurar que las necesidades del sector industrial sean satisfechas por la educación y capacitación vocacional. Esto ha formado parte de una amplia reforma macroeconómica que busca asegurar que el sector industrial sea competitivo en la economía global.

- Los problemas principales que se han observado son: a) Sistemas demasiado reglamentados, inflexibles y complejos para el sector industrial, establecidos por una burocracia recelosa. b) Falta de previsión para asegurarse que aquellos que debían impartir la capacitación participaran en el desarrollo del sistema y fueran lo suficientemente aptos para instrumentarlo.

- A pesar de todo, el sistema ha sido bien recibido en amplios sectores de la industria, permitiéndoles articular sus demandas con mayor claridad que en el pasado y poder escoger entre muchos oferentes a sus proveedores de educación y capacitación.

La EBNC se ha aplicado en los países más industrializados, inicialmente en la formación vocacional (técnica y tecnológica) en y para el trabajo. Sin embargo, ya la Conferencia mundial sobre la educación superior, convocada por la UNESCO en $1998^{34}$, estableció que en un contexto económico caracterizado por los cambios y la aparición de nuevos modelos de producción basados en el saber y sus aplicaciones, así como en el tratamiento de la información, deben reforzarse y renovarse los vínculos entre enseñanza superior, el mundo del trabajo y otros sectores de la sociedad, para lo cual dicha conferencia trazó los siguientes lineamientos:

- Combinar estudio y trabajo.

- Intercambiar personal entre el mundo laboral y las instituciones de educación superior.

- Revisar los planes de estudio para adaptarlos mejor a las prácticas profesionales.

- Crear y evaluar conjuntamente modalidades de aprendizaje, programas de transición, de evaluación y reconocimiento de los saberes previamente adquiridos por los estudiantes.

- Integrar la teoría y la formación en el trabajo.

\footnotetext{
${ }^{33}$ lbid, p. 20-37

${ }^{34}$ UNESCO. "Declaración mundial sobre la educación superior en el siglo XXI: Visión y acción". Conferencia mundial sobre la educación superior. París, octubre de 1998. En: ASOCIACIÓN COLOMBIANA DE UNIVERSIDADES. Cuadernos Ascun. Bogotá: Ascun, 1999, № 7, p. 68-69.
} 
De lo anterior se infiere que los nexos entre la educación superior y el trabajo requieren de una formación profesional basada en competencias no sólo laborales, sino también comunicativas, intelectuales y socioafectivas, para el desempeño en los complejos, inestables, inciertos y conflictivos ámbitos organizacionales y sociales de la práctica profesional.

La relación entre competencias intelectuales y socioafectivas se encuentra presente en los clásicos de la psicología que vienen investigando este tema. Por ejemplo, Goleman sostiene que "en un sentido muy real, tenemos dos mentes, una que piensa y otra que siente, ${ }^{35}$. En la mente emocional habita la inteligencia emocional, entendida como el conjunto de capacidades para motivarse, persistir frente a las decepciones, controlar el impulso, regular el humor y evitar que los trastornos disminuyan el pensamiento, mostrar empatía y abrigar esperanza ${ }^{36}$.

Cooper y Sawaf definen la inteligencia emocional como la capacidad de sentir, entender y aplicar eficazmente el poder y la agudeza de las emociones como fuente de energía humana, información, conexión e influencia ${ }^{37}$. Además, consideran que "gran parte de la sabiduría creativa de cada persona existe en el núcleo de la inteligencia emocional" y que "la intuición está íntimamente vinculada con la inteligencia emocional y puede ser de inmenso valor para el éxito profesional y personal" ${ }^{38}$. Einstein ${ }^{39}$ expresó en cierta oportunidad: "Nunca descubrí nada con mi mente racional".

Morin $^{40}$ considera los siguientes elementos en la relación inteligencia-afectividad:

- En el mundo mamífero, y sobre todo en el humano, el desarrollo de la inteligencia es inseparable del de la afectividad (por ejemplo, curiosidad, pasión), que es a la vez resorte de la investigación filosófica o científica.

- La afectividad puede asfixiar el conocimiento pero también puede fortalecerlo.

- Existe una relación estrecha entre la inteligencia y la afectividad: la facultad de razonamiento puede ser disminuida y hasta destruida por un déficit de emoción, el debilitamiento de la capacidad para reaccionar emocionalmente puede llegar a ser la causa de comportamientos irracionales.

- No existe un estado superior de la razón que domine la emoción sino un bucle inteligenciaafecto.

- De cierta manera, la capacidad de emoción es indispensable para el establecimiento de comportamientos racionales.

\footnotetext{
${ }^{35}$ GOLEMAN, Daniel. La inteligencia emocional. Buenos aires: Javier Vergara, 1999, p. 27.

${ }^{36}$ lbid.

${ }^{37}$ COOPER, Robert K y SAWAF, Ayman. La inteligencia emocional aplicada al liderazgo y a las organizaciones. Bogota: Norma, 1998,

p. 14.
38 lbid, p. $5-6$.

${ }^{39}$ Cit. En: COOPER y SAWAF, op. cit.

${ }^{40}$ MORIN, Edgar. Los siete saberes necesarios para la educación del futuro. Bogotá: Imprenta nacional, 2000, p. 18
} 
Así las cosas, de no darse en la práctica la proporcionada relación pensamiento-emoción, un profesional puede ser muy brillante intelectualmente, pero muy torpe afectivamente. Un ejecutivo altamente preparado pero insoportable puede llevar al traste la más importante empresa.

En educación, asumir el proceso pedagógico como "reflexión en la acción",41 (pensar-actuar-pensar) favorece considerablemente el aprendizaje y desarrollo de las competencias. En palabras de John Dewey, el pensamiento reflexivo consiste en "darle vueltas a un tema en la cabeza y tomárselo en serio con todas sus consecuencias" ${ }^{42}$. La "reflexión en la acción" puede manifestarse en las siguientes formas ${ }^{43}$.

- Acciones espontáneas y rutinarias que pueden asumirse como estrategias para resolver una tarea o problema en una situación particular. En este caso, el conocimiento en la acción es tácito, formulado espontáneamente sin una reflexión consciente. Puede producir los resultados esperados siempre y cuando la situación se mantenga dentro de los límites que hemos aprendido a considerar como normales.

- Acciones rutinarias que producen sorpresas, resultados inesperados, agradables o desagradables, que pueden no corresponder con nuestro conocimiento en la acción, pero que llaman nuestra atención.

- Sorpresas conducentes a la reflexión dentro de la acción presente. La reflexión, al menos en alguna medida, resulta consciente, aunque no se produzca necesariamente por medio de palabras. El pensamiento se centra en el hecho que nos sorprende y, simultáneamente, sobre sí mismo.

- Función crítica que cuestiona las suposiciones surgidas en la acción. Entonces se pueden reestructurar estrategias de acción, de comprensión de los fenómenos o de las maneras de formular los problemas.

- Reflexiones que dan lugar a la experimentación "in situ", pues pueden idearse y probarse nuevas acciones que pretenden explorar los hecho recién observados, verificar la comprensión original de los mismos o afirmar los pasos que hemos seguido.

La "reflexión en la acción" abarca el "conocimiento en la acción",44, aquel que se revela en las acciones inteligentes, ya sean observables al exterior o que se den internamente en las personas. En ambos casos el conocimiento está en la acción, se evidencia a través de la ejecución espontánea y hábil y, paradójicamente, puede hacerse explícito verbalmente.

\footnotetext{
${ }^{41}$ SCHON, Donald A. La formación de profesionales reflexivos. Barcelona: Paidós, 1992, p.36.

42 DEWEY, John. Cómo pensamos: Nueva exposición de la relación entre pensamiento reflexivo y proceso educativo. Barcelona: Paidós, 1989, p. 21.

${ }^{43}$ SCHON, op. cit. p.36.

${ }^{44}$ SCHON, op. cit., p. 35.
} 
El conocimiento en la acción requiere de la actitud investigativa ${ }^{45}$, concebida como una manera vivencial y práctica de conocer que facilita la capacidad de duda, búsqueda, aventura y reflexión permanente y sistemática a través de la pregunta reflexiva en torno a múltiples interrogantes, fenómenos y situaciones. De esta manera, en los procesos de enseñanza y aprendizaje siempre habrá una pregunta que exigirá respuesta. La pregunta, así asumida, se convierte en el arma predilecta contra la rutina, ese enemigo oculto pero poderoso que acecha constantemente el quehacer pedagógico.

El conocimiento en la acción contribuye a que no seamos presa de las prácticas pedagógicas academicistas, en las cuales la teoría y los conocimientos se asumen como fines en sí mismos, con poca o ninguna aplicación práctica. Por ello, las estrategias pedagógicas deben tener siempre presente el desempeño, lo cual implica:

- Destacar la relevancia y pertinencia de los contenidos que se aprenden.

- Evitar el fraccionamiento tradicional de los conocimientos y facilitar su integración.

- Generar aprendizajes aplicables a situaciones complejas.

- Estimular, facilitar y provocar la autonomía personal del aprendiz.

- Harris, citado por Mertens ${ }^{46}$, considera que los programas formativos basados en competencias requieren cambios en los enfoques curriculares, en las estrategias pedagógicas y en el rol tradicional asignado al docente y al estudiante. En tal sentido, propone:

- Competencias identificables, verificables y de conocimiento público. Cuando el estudiante sabe lo que se espera de él se muestra más eficiente y motivado.

- Instrucción dirigida al desarrollo y evaluación individual de cada competencia.

- Evaluación teniendo en cuenta el conocimiento, las habilidades, las actitudes y el desempeño como principales fuentes de evidencia.

- Progreso de los estudiantes al ritmo de cada uno.

- Instrucción individualizada al máximo posible.

- Énfasis puesto en los logros.

- Participación de los estudiantes en la elaboración de las estrategias de aprendizaje.

\footnotetext{
${ }^{45}$ POSADA, Rodolfo. La investigación en el aula: Una alternativa para el trabajo docente. Santa Marta: Universidad del Magdalena, 1997.

${ }^{46}$ HARRIS. Cit. en: MERTENS, Leonard. Competencia Laboral: Sistemas, surgimiento y modelos. CINTERFOR. Montevideo, 1997.
} 
- Experiencias de aprendizaje guiadas por una permanente retroalimentación.

- Amplia variedad de materiales didácticos, con orientación del aprendizaje hacia la solución de problemas, más que a la repetición de contenidos.

- Programas modulares y abiertos que faciliten el movimiento y la reincorporación de los estudiantes en diferentes momentos.

Muchos estudios sobre las profesiones han encontrado que los recién egresados tienen problemas al enfrentarse al mundo laboral en sus primeros años ${ }^{47}$, lo que ha conducido a experimentar con nuevos enfoques curriculares. Uno de ellos es el currículo basado en problemas, actualmente bien establecido en una variedad de campos profesionales y en un importante número de universidades a nivel internacional. Este enfoque trata los problemas reales que enfrentan las profesiones como punto de partida de un currículo. Sus características principales son:

- La utilización de materiales que simulan o tratan situaciones de la vida real.

- La disponibilidad de recursos para permitir a los educandos aclarar los problemas y enfrentarlos.

- El trabajo cooperativo de los educandos con acceso a un tutor.

- El tratamiento de los problemas uno a la vez, diferente a los cursos basados en materias, donde se trata de hacer muchas cosas al tiempo.

Sostiene Gonczi ${ }^{48}$ que el enfoque de competencias, en su forma ortodoxa, se ha concentrado en un análisis detallado de la profesión/ocupación, mientras que el aprendizaje basado en problemas (ABP) se sustenta en lo que se considera como la mejor práctica de aprendizaje y en la necesidad de ciertas competencias (particularmente las de "orden mayor": pensamiento crítico, comunicación, etc.) para solucionar los problemas de la profesión. Sin embargo, ambos enfoques deben terminar en el mismo punto, ya que el propósito es el practicante competente. En este sentido, cualquier programa diseñado para desarrollar experiencias en un dominio particular deberá tener en cuenta la manera como los expertos fueron capaces de utilizar sus experiencias con propósitos de aprendizaje.

\section{EVALUACIÓN BASADA EN COMPETENCIAS}

La evaluación es, quizás, el más importante de todos los procesos involucrados en la educación, sobre todo en la educación superior, pues a través de él se decide la suerte del estudiante. Este puede evadir, a veces con mucha dificultad, las metodologías de enseñanza inapropiadas, pero es casi imposible

\footnotetext{
${ }^{47}$ GONCZI, Andrew. Problemas asociados con la implementación de la educación basada en la competencia: de lo atomístico a lo holístico. En: CINTERFORT/OIT. Formación basada en competencia laboral. 1997, p. 165-166.

${ }^{48}$ Ibid, p. 166.
} 
escapar de las formas evaluativas inconvenientes que usan algunos docentes, sobre todo cuando se evalúa para controlar y decidir con base en "ganar-perder".

A juicio de McDonald y colaboradores ${ }^{49}$, las prácticas tradicionales de evaluación presentan los siguientes inconvenientes:

- Se concentran sobre aquellas materias más fáciles de evaluar, lo cual conduce a un énfasis exagerado en la memorización y en la obtención de habilidades en los niveles más bajos.

- Estimula a los estudiantes a focalizar sobre aquellos tópicos que son evaluados, a expensas de los que no lo son.

- Los estudiantes otorgan más importancia a las tareas cuya evaluación se requiere para obtener una calificación, pero no así a las que no necesitan este requisito.

- Los estudiantes adoptan métodos de aprendizaje indeseables, influidos por las estrategias inapropiadas de evaluación.

- Los estudiantes muchas veces memorizan conceptos equivocados sobre aspectos claves de las materias que han aprobado, a pesar de lograr un buen desempeño en las evaluaciones.

- Los estudiantes exitosos buscan apuntes de los docentes con el fin de identificar lo que es importante para aprobar las evaluaciones formales. En consecuencia ignoran materiales primordiales pero no evaluables.

Agrega McDonald ${ }^{50}$ que como resultado de lo anterior se concluye que los métodos de evaluación existentes puden tener efectos completamente opuestos a los que buscan. Afortunadamente, el tema de la relación entre competencia, aprendizaje y evaluación ha vuelto a colocarse en el centro de la escena y es posible mirar nuevamente los modos en que la evaluación puede complementar dos requerimientos necesarios: evaluar la competencia y tener un efecto beneficioso sobre el proceso de aprendizaje.

La buena evaluación no supone sólo encontrar un método apropiado y usarlo adecuadamente, pues en ella siempre se obtienen consecuencias no buscadas. Según algunas experiencias ${ }^{51}$, en determinadas circunstancias, los estudiantes aprenden a adoptar procedimientos superficiales o mecánicos para estudiar (tales como los basados en la memorización) y en otras asumen métodos más profundos o significativos. Sea lo uno o lo otro, ellos están parcialmente influidos por la naturaleza y forma de la evaluación. Por ejemplo, si tienen la idea de que la memorización funciona en las pruebas de opción múltiple, persistirán en esta estrategia a pesar de estar convencidos de que ella no les beneficiará. Además, los estudiantes no responden solamente a las exigencias de una materia en particular, ya que en el momento de una

\footnotetext{
${ }^{49}$ MACDONALD, Rod, et al. "Nuevas perspectivas sobre la evaluación". UNESCO, París, 1995. En: CINTERFOR-OIT. Competencias laborales en la formación profesional. Boletín Técnico Interamericano de Formación Profesional. № 149, mayo-agosto de 2000 , p. 44. ${ }^{50}$ Ibid, p. 45.
} 
evaluación traen consigo la totalidad de sus experiencias previas de aprendizaje y evaluación, lo cual se extiende más allá de las materias a las que asisten en ese instante o a las precedentes inmediatamente.

Ante las reflexiones anteriores, es pertinente preguntarse: ¿por qué la evaluación basada en competencias? McDonald ${ }^{52}$ considera que un enfoque de evaluación basado en competencias es altamente apropiado en la formación profesional, ya que permite:

- Asegurar que la enseñanza y la evaluación estén al servicio de los resultados esperados, en lugar de los cursos desarrollados o el tiempo utilizado.

- Facilitar el otorgamiento de créditos a las competencias adquiridas en otros lugares.

- Ayudar a los estudiantes a comprender claramente lo que se espera de ellos si quieren tener éxito en el curso.

- Informar a los empleadores potenciales lo que significa una calificación particular.

El proceso de adquisición y/o desarrollo de las competencias en el ámbito educativo requiere que éstas se prevean a través de logros o metas. El logro esperado es lo que se desea obtener del estudiante en su proceso formativo y que se expresa en el desempeño, sea éste teórico, práctico o teórico-práctico. El logro alcanzado es el resultado, lo que ya es una realidad. Por lo tanto, la evaluación comparará hasta dónde los logros esperados se convierten en logros alcanzados. Los indicadores de logros son señales, evidencias, sobre el desempeño del estudiante. Desde esta perspectiva, ¿cómo concebir la evaluación? "Evaluar es comprender", sostiene Santos ${ }^{53}$. Pero, ¿qué comprender?

En la evaluación basada en competencias, los profesores emiten juicios fundamentados en una variedad de evidencias que demuestran hasta dónde un estudiante satisface los requisitos exigidos por un estándar o conjunto de criterios. Para ello deben ${ }^{54}$ :

- Establecer los criterios de evaluación. Éstos deben detallarse suficientemente (qué evaluar, logros e indicadores de logros, etc.) y ser familiares a los estudiantes para que ellos puedan juzgar hasta dónde dichos criterios han sido satisfechos.

- Decidir la evaluación con base en la comparación entre los logros esperados y las evidencias detectadas

- Registrar los resultados

- Revisar los procedimientos usados en la evaluación

\footnotetext{
${ }^{51}$ Ibid, p. 45-46

52 lbid, p. 51.

${ }^{53}$ SANTOS GUERRA, Miguel Ángel. Evaluar es comprender. Buenos Aires: Magisterio Río de la Plata, 1998.
} 
Los enfoques integrales de evaluación del desempeño combinan conocimiento, entendimiento, solución de problemas, habilidades técnicas, actitudes y ética de la evaluación. Una evaluación integrada u holística se caracteriza por estar orientadas a problemas, ser interdisciplinaria, cubrir grupos de competencias, exigir habilidades analíticas y combinar la teoría con la práctica ${ }^{55}$.

La evaluación ha estado influenciada fuertemente por concepciones centradas en el control, con el fin de vigilar y monitorear la presencia de los estudiantes en el sistema educativo. De allí términos como "perdió", "ganó", "aplazó", "superó", "recuperó", "habilitó", para referirse a los logros de los estudiantes. Pero, ¿qué se "pierde" o "gana", qué se "recupera" o "habilita”? Si la disyuntiva es "ganar" o "perder", ¿no radicará aquí la actitud de algunos estudiantes cuando se roban los exámenes, se copian de los compañeros durante las evaluaciones o usan los "recordatorios" o "machetes"? ¿Acaso no se estará transmitiendo subliminalmente el mensaje "ganar a cualquier precio", mintiendo y engañando? Desde esta perspectiva, los resultados deficitarios se atribuyen, por lo general, a los estudiantes, quienes son catalogados como "vagos", "mal preparados", "no saben leer", "no comprenden", etc. Terminan siendo los "pacientes" "víctimas" de la evaluación. Todas estas concepciones se encuentran impregnadas fuertemente en la mente y el corazón de no pocos profesores, estudiantes y padres de familia, sin que medie mayor reflexión sobre el profundo significado que poseen.

A través del control, la evaluación va marginado del sistema educativo a quienes no aprueban los exámenes, permaneciendo en él sólo aquellos que los superan, sin que se investigue seriamente qué sucede con los estudiantes "perdedores". Dos preguntas de grueso calibre continúan sin clarificarse plenamente: ¿Hasta dónde existe una relación entre éxito en las evaluaciones y éxito en el desempeño laboral? ¿Hasta dónde los resultados de los exámenes, sobre todo escritos, ocultan otras competencias que deben poseer los futuros profesionales?

Todas estas ideas y prácticas desdibujan la verdadera naturaleza de la evaluación. Desde la perspectiva cualitativa la esencia de la evaluación es comprender lo que sucede en los procesos de aprendizaje y enseñanza. Es mucho más que un momento final del proceso formativo en el que se comprueban los logros, es una actividad permanente, reflexiva, compartida entre estudiantes y profesores y apoyada en evidencias de diversos tipos, no exclusivamente los exámenes, sobre todo cuando éstos se reducen a los denominados "primeros parciales", "segundos parciales" y "exámenes finales", lenguaje y prácticas muy arraigadas en la educación superior.

$\operatorname{Santos}^{56}$ se refiere a las siguientes funciones de la evaluación:

- Diagnostico: permite conocer las ideas de los estudiantes, los errores que cometen, las principales dificultades en que se encuentran, los logros más importantes alcanzados. Desde luego, los profesores también debemos autodiagnosticarnos.

\footnotetext{
${ }^{54}$ MACDONALD, op. cit. p. 49

${ }^{55}$ Ibid, p. 168.

${ }^{56}$ SANTOS, op. cit. p. 23.
} 
- Dialogo: escenario para reflexionar y compartir sobre la enseñanza y el aprendizaje, en el cual intervengan los estudiantes, los profesores, las familias y otros sectores sociales preocupados por la educación.

- Comprensión: facilita la interpretación, argumentación y proposición de lo que sucede en los procesos de enseñanza y aprendizaje. Esta es la principal característica de la evaluación, su valor esencial.

- Retroalimentación: facilita la reorientación de los procesos de enseñanza y aprendizaje. No sólo en lo referente al trabajo académico de los estudiantes, sino también a la planificación de la enseñanza, a los contextos de aprendizaje y al desempeño docente.

- Aprendizaje: es un momento muy propicio para que profesores y estudiantes detecten si las competencias y los conocimientos adquiridos, así como las pedagogías usadas son adecuados, claros, pertinentes, significativos y relevantes.

La evaluación cualitativa, como valoración de los logros, analiza y verifica hasta dónde éstos se han alcanzado, hasta dónde se es competente. Desde esta mirada, evaluar es atribuir sentido y significado a los logros e indicadores de logros. Esta interpretación de los logros se fundamenta en determinadas concepciones pedagógicas y en la naturaleza de los saberes y las disciplinas.

La evaluación cuantitativa con mayor arraigo escolar muy tradicional, más que valorar logros, comprender y detectar niveles de desempeño, mide qué tanta información posee el estudiante, según el número de respuestas correctas en los exámenes, sobre todo cuando se responde sin mayor comprensión, "a punta de memoria". La evidencia más clara de este proceder es prohibir a los estudiantes usar fuentes y medios (textos, calculadoras, datos, etc.) y conversar entre ellos durante los exámenes, prácticas éstas esenciales en la vida profesional cuando se ignora algo. Se trata, nada más ni nada menos, de una evaluación memorística, artificial, alejada del verdadero desempeño profesional ¿Hasta dónde este tipo de evaluación refleja las competencias intelectuales y comunicativas de los estudiantes que posteriormente serán transferidas a la práctica profesional?

En cuanto a los promedios estadísticos, asumidos como indicadores cuantitativos de desempeño académico, éstos distorsionan la naturaleza del aprendizaje, del conocimiento y de las competencias. Por ejemplo, si un estudiante $X$ en un determinado momento alcanza una calificación de 2.5 debido al insuficiente dominio de un tema o a la escasa habilidad para realizar un trabajo o práctica, pero más adelante supera tales falencias y obtiene una nota de 4.0, entonces no se puede decir que sabe "a medias" (3.25) como resultado de promediar las dos calificaciones. Sin embargo, el estudiante "pasa" la asignatura. Pero, ¿qué acontece con el resto de su rendimiento académico, con sus competencias? De persistir esta situación a lo largo de los estudios, ¿qué ocurrirá con su futuro desempeño profesional? De allí la necesidad de saber, en verdad, cuales son los logros de los estudiantes, por medio de unos indicadores que comprueben la adquisición de las competencias y de los conocimientos esperados. 
El siguiente gráfico representa una opción, que denominamos evaluación participativa, experimentada con estudiantes universitarios, en la cual los juicios valorativos son elaborados conjuntamente por los estudiantes y el profesor.

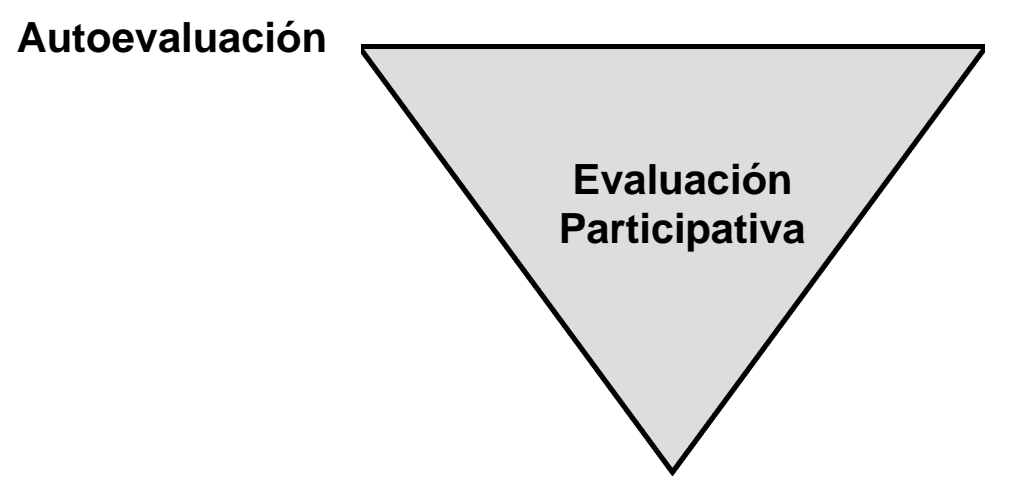

\section{Coevaluación}

\section{Heteroevaluación}

El procedimiento en la evaluación participativa puede desarrollarse así:

- El estudiante se autoevalúa individualmente (autoevaluación)

- Los estudiantes se evalúan entre sí, organizados en grupos no mayores de cinco (cooevaluación intragrupo). Los grupos también pueden evaluarse entre ellos (cooevaluación intergrupo).

- El profesor evalúa (heteroevaluación) teniendo en cuenta la autoevaluación y la cooevaluación, y coordina el análisis e interpretación de los resultados, realizado conjuntamente con los estudiantes.

Todo el procedimiento anterior se fundamenta en las competencias y los conocimientos adquiridos por el estudiante. Por ejemplo, en un curso sobre Desarrollo humano, el profesor plantea la siguiente competencia a sus estudiantes: "interpretar y argumentar las principales teorías psicológicas sobre el desarrollo humano". Al momento de evaluar tiene en cuenta el siguiente formato, tanto para la autoevaluación, la cooevaluación (inter e intragrupo) y la heteroevaluación: 
ACTIVIDAD:

FECHA:

ESTUDIANTE O GRUPO EVALUADO:

ESTUDIANTE O GRUPO EVALUADOR:

COMPETENCIA: Interpretar y argumentar las principales teorías psicológicas sobre el desarrollo humano.

INSTRUCCIÓN: Marcar con una $\mathbf{X}$ la letra correspondiente a cada indicador:

Excelente (E) - Sobresaliente (S) - Aceptable (A) - Insuficiente (I) - Deficiente (D)

\begin{tabular}{|l|c|c|c|c|c|}
\hline \multicolumn{1}{|c|}{ INDICADORES DE LOGROS } & \multicolumn{5}{|l|}{ VALORACIÓN } \\
\hline 1. Relaciona los nuevos conocimientos con sus ideas previas & E & S & A & I & D \\
\hline 2. Aplica los conocimientos correctamente en situaciones específicas & E & S & A & I & D \\
\hline 3. Compara los conocimientos entre sí & E & S & A & I & D \\
\hline 4. Identifica ideas claves & E & S & A & I & D \\
\hline 5. Organiza ideas (ensayos, esquemas, mapas conceptuales, etc.) & E & S & A & I & D \\
\hline 6. Ejemplifica con base en la(s) teoría(s) estudiada(s) & E & S & A & I & D \\
\hline 7. Aporta ideas nuevas & E & S & A & I & D \\
\hline 8. Investiga otras fuentes & E & S & A & I & D \\
\hline 9. Intercambia conceptos y opiniones & E & S & A & I & D \\
\hline 10. Argumenta clara y coherentemente & E & S & A & I & D \\
\hline 11. Vocaliza adecuadamente & E & S & A & I & D \\
\hline 12. Relaciona las ideas con el contexto & E & S & A & I & D \\
\hline 13. Responde preguntas correctamente & E & S & A & I & D \\
\hline 14. Plantea interrogantes interesantes & E & S & A & I & D \\
\hline EVALUACIÓN DEFINITIVA & E & S & A & I & D \\
\hline SUGERENCIAS (FORTALEZAS Y DEBILIDADES): & & & & \\
\hline & & & & \\
\hline
\end{tabular}


La evaluación definitiva de la actividad desarrollada se realiza teniendo en cuenta la media (el mayor número de letras), la cual evidencia la tendencia predominante. Así, si un estudiante, entre los 14 indicadores de logros obtuvo ocho Sobresalientes (S), entonces su nota definitiva será S.

Actualmente, la forma de evaluación preponderante, casi única, es la que realiza el profesor a los estudiantes (heteroevaluación). Pero, ¿por qué no involucrar a los estudiantes permitiéndoles que se autoevalúen y coevalúen (unos a otros)? En nuestra experiencia hemos comprobado que estos procedimientos contribuyen en gran medida a consolidar la responsabilidad y el autocontrol en los estudiantes valores fundamentales en el ser humano para un buen desempeño laboral y personal. Pero, ¿será que los profesores tememos perder el poder que nos ha otorgado la evaluación para incidir en el porvenir de los estudiantes? ¿Será que no creemos en los estudiantes? Sin embargo, muchas veces sermoneamos sobre la educación en valores como esencia de la formación integral.

\section{COMPETENCIAS Y TRABAJO INTERDISCIPLINARIO}

La formación con base en competencias conlleva integrar disciplinas, conocimientos, habilidades, prácticas y valores. La integración disciplinar es parte fundamental de la flexibilización curricular, particularmente de los planes de estudio, en aras de formar profesionales más universales, aptos para afrontar las rápidas transformaciones de las competencias y los conocimientos.

Según Senge ${ }^{57}$, una disciplina es un cuerpo teórico y técnico que se debe estudiar y dominar para llevarlo a la práctica, que permite adquirir ciertas aptitudes y competencias, lo cual supone un compromiso constante con el aprendizaje, pasar la vida dominando disciplinas. Piaget ${ }^{58}$ propone las siguientes dimensiones de integración disciplinar:

- Multidisciplinariedad: es el nivel inferior de integración, que ocurre cuando alrededor de un interrogante, caso o situación, se busca información y ayuda en varias disciplinas, sin que dicha interacción contribuya a modificarlas o enriquecerlas. Esta puede ser la primera fase de la constitución de equipos de trabajo interdisciplinario.

- Interdisciplinariedad: es el segundo nivel de integración disciplinar, en el cual la cooperación entre disciplinas conlleva interacciones reales, es decir, una verdadera reciprocidad en los intercambios y, por consiguiente, un enriquecimiento mutuo. En consecuencia, llega a lograrse una transformación de los conceptos, las metodologías de investigación y de enseñanza. Implica también, a juicio de Torres $^{59}$, la elaboración de marcos conceptuales más generales en los cuales las diferentes disciplinas en contacto son a la vez modificadas y pasan a depender unas de otras.

\footnotetext{
${ }^{57}$ SENGE, Peter M. La quinta disciplina. El arte y la práctica de la organización abierta al aprendizaje. Barcelona: Granica, 1996, p. 20. ${ }^{58}$ PIAGET, Jean. La epistemología de las relaciones interdisciplinarias. En: L. APOSTEL, G. BERGERR, A. BRIGGS Y G. MICHAUD. Interdisciplinariedad. Problemas de la enseñanza y de la investigación en la Universidades. México: Asociación Nacional de Universidades e Institutos de Enseñanza Superior, 1979, p. 153-171.

${ }^{59}$ TORRES SANTOME, Jurjo. Globalización e interdisciplinariedad: El curriculum integrado. Madrid: Morata, 1996.
} 
- Transdisciplinariedad: es la etapa superior de integración disciplinar, en donde se llega a la construcción de sistemas teóricos totales (macrodisciplinas o transdisciplinas), sin fronteras sólidas entre las disciplinas, fundamentadas en objetivos comunes y en la unificación espistemológica y cultural.

El siguiente gráfico, diseñado con base en las anteriores dimensiones, a manera de ejemplo, muestra la integración de tres disciplinas ( $\mathrm{A}, \mathrm{B}$ y $\mathrm{C}$ ) como un proceso ascendente, cuyos límites se mueven desde el mero acercamiento (multidisciplinariedad), pasando por el debilitamiento, la borrosidad e intersección (interdisciplinariedad), hasta la pérdida de los mismos, en una lógica de lo simple a lo complejo. En este proceso no existen demarcaciones fijas e infranqueables, de tal forma que la dimensión menos compleja puede contener elementos de la más compleja y transformarse en ésta.

\section{Integración disciplinar}

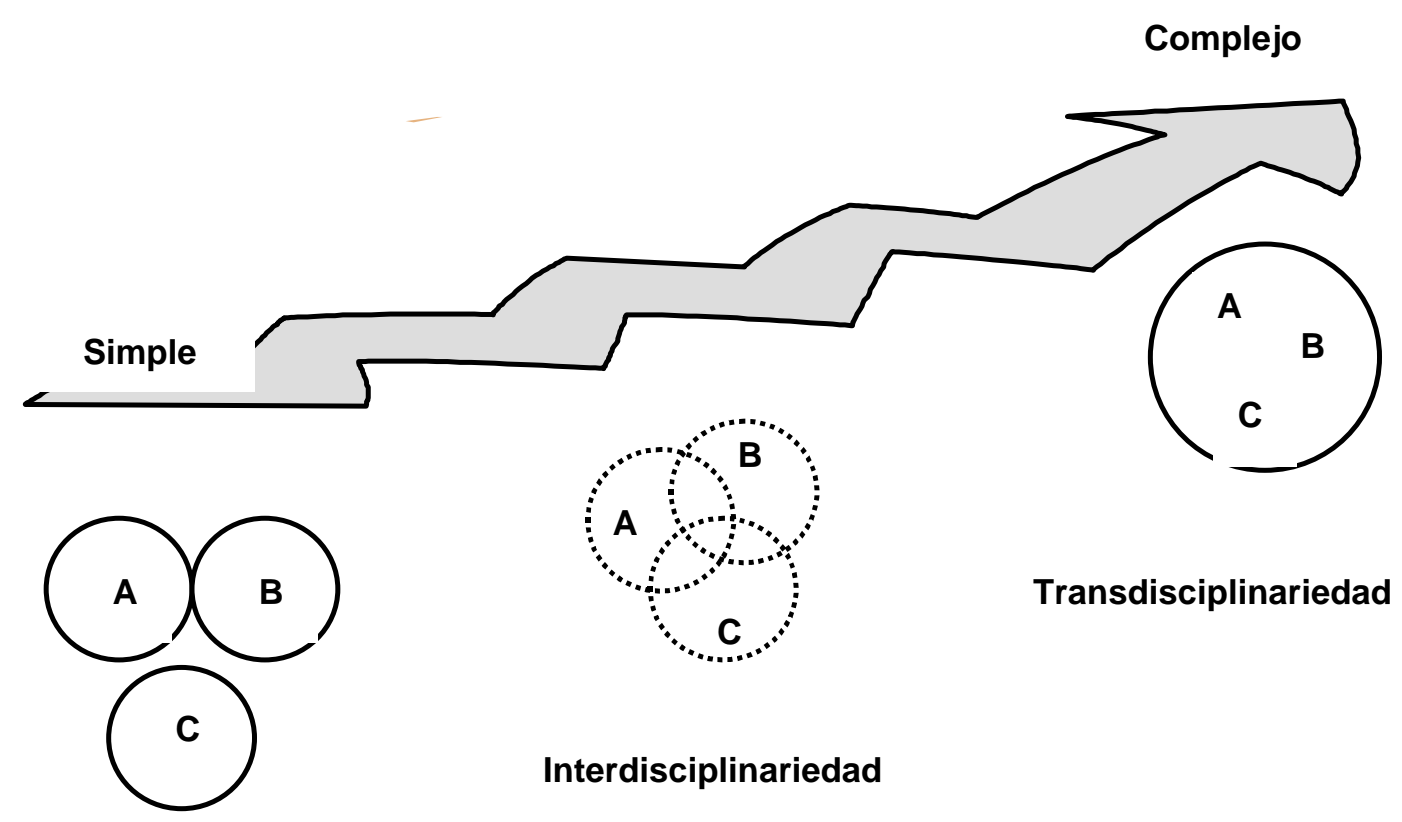

\section{Multidisciplinariedad}

La actividad docente fundamentada en estos tipos de integración disciplinar permite que los conceptos, marcos teóricos, procedimientos y demás elementos con los que tienen que trabajar profesores y estudiantes se organicen en torno a unidades más globales, a estructuras conceptuales y metodológicas compartidas por varias disciplinas.

Las actividades académicas de integración disciplinar contribuyen al afianzamiento de ciertos valores en profesores y estudiantes: flexibilidad, confianza, paciencia, intuición, pensamiento divergente, 
sensibilidad hacia las demás personas, aceptación de riesgos, aprender a moverse en la diversidad, aceptar nuevos roles, entre otros ${ }^{60}$.

El trabajo académico integrado, en cualquiera de sus formas, requiere de las siguientes acciones:

- Trabajar en equipo.

- Establecer criterios para la integración.

- Desarrollar tormentas de ideas para seleccionar y precisar los conceptos, temas, disciplinas, prácticas y competencias a integrar.

- Establecer los tipos de relaciones entre las disciplinas.

- Determinar los tiempos para desarrollar los temas, problemas, etc.

- Evaluar continua y formativamente el proceso de integración disciplinar.

- Recolectar toda la información posible sobre experiencias en este campo.

\section{APRENDIZAJE AUTÓNOMO DEL ESTUDIANTE Y TUTORÍA PROFESORAL}

El sistema de créditos en la educación superior colombiana otorga gran importancia al aprendizaje autónomo del estudiante, reconociéndole el doble del tiempo dedicado al trabajo académico con acompañamiento del profesor. En tal sentido, la universidad certificará tanto el aprendizaje del estudiante en compañía del profesor como el que realice independientemente. Este último es calve para el pleno desarrollo autónomo del estudiante, establecido en la ley 30 de 1992:

- "Artículo 1․ La Educación Superior es un proceso permanente que posibilita el desarrollo de las potencialidades del ser humano de una manera integral"... y el "pleno desarrollo de los alumnos y su formación académica o profesional" (destacado nuestro).

- "Artículo 4․ La Educación Superior, sin perjuicio de los fines específicos de cada campo del saber, despertará en los educandos un espíritu reflexivo, orientado al logro de la autonomía personal, en un marco de libertad de pensamiento y de pluralismo ideológico que tenga en cuenta la universalidad de los saberes y la particularidad de las formas culturales existentes en el país. Por ello, la Educación Superior se desarrollará en un marco de libertades de enseñanza, de aprendizaje, de investigación y de cátedra" (destacado nuestro).

Para el cumplimiento de los anteriores propósitos es recomendable aplicar y desarrollar pedagogías que estimulen y favorezcan en alumnos y profesores procesos y actividades conducentes a:

\footnotetext{
${ }^{60}$ TORRES, op. cit. p. 69.
} 
- Desarrollar la capacidad y actitud de aprender, investigar, construir e innovar, en correspondencia con los continuos cambios.

- Aprender a trabajar en equipo, desarrollando la autonomía intelectual y la responsabilidad individual y colectiva.

- Adquirir importantes niveles de autoestima y espontaneidad para la libre discusión, las formas racionales de argumentación, las competencias comunicativas, socioafectivas y profesionales, la articulación teoría-práctica, la búsqueda y uso de información relevante, la familiaridad con los idiomas en los que circula la bibliografía e información requerida.

- Desmitificar la ciencia, el texto y el profesor como fuentes únicas de saber.

Acorde con estos criterios, la docencia en la universidad debe ser ejercida por profesores estudiosos, competentes, comprometidos, conocedores profundos de sus saberes y disciplinas, como también de su desempeño docente (competencias y conocimientos pedagógicos), sensibles a las transformaciones sociales e institucionales, sobre todo a las innovaciones pedagógicas y curriculares. Así podrá contribuir a lograr las expectativas de sus estudiantes, detectar sus debilidades, desarrollar sus fortalezas y contrarrestar las tendencias perturbadoras presentes en la sociedad.

Los estudiantes, por su parte, como miembros fundamentales de la comunidad académica, deben desarrollar una gran voluntad de saber, de adquirir las competencias y los conocimientos necesarios para su propia realización y contribuir al progreso del entorno en el que se mueven.

Con el fin de alcanzar logros personales y académicos significativos, los estudiantes deben poseer una gran disciplina y constante voluntad de trabajo, exigir sus derechos pero también cumplir sin laxitud sus obligaciones, participar en la consolidación de la institución, esforzarse por acrecentar con espíritu crítico pero constructivo el conocimiento, buscar la integración con los compañeros de disciplinas diferentes a las suyas para complementar fuera del aula el conocimiento adquirido en ella. Es imperativo que los estudiantes reflexionen sobre su deber ser, el alcance de su misión en su vida universitaria y como futuros profesionales al servicio de la sociedad.

Al asumir estas orientaciones, las actividades académicas deben tener propósitos claros acerca de lo específico que se pretende, evitando al máximo generalidades y teorizaciones sin referentes concretos ni aplicabilidad. Es necesario, entonces, favorecer la experimentación de situaciones probables, de enfoques y modalidades de trabajo académico. La actividad tutorial es clave en todo esto. El profesorado debe contar con el tiempo necesario para ello. 
Morreau, citado por López y Oliveros $^{61}$, se ha referido a la tutoría en la universidad como una "pedagogía del acompañamiento". El momento evolutivo del estudiantes universitario y las características del mismo requieren que su acompañamiento sea lo menos directivo e intervencionista posible, tendiente a facilitar su nivel de autonomía y prestar la ayuda necesaria para que establezca, evalúe y experimente un proyecto de vida personal, realista. Referirse a un proyecto de vida es hablar de intencionalidad (hacer explícitos los deseos e intenciones), de desarrollo (manifestar el deseo de crecer en un determinado sentido), de actividad (establecer acciones para alcanzar las metas) y de toma de conciencia e interiorización (reflexionar sobre si mismo). Entre las ventajas que se le pueden atribuir a la construcción de un proyecto de vida así concebido están ${ }^{62}$ :

- El protagonismo que el estudiante asume.

- El enfoque globalizado y la coherencia que presenta.

- La capacidad de anticipar que supone.

- Los mecanismos de reflexión, interiorización, toma de decisiones, etc. que pone en juego.

- La postergación de recompensas que muchas veces implica.

- Rodríguez y Gallego ${ }^{63}$ dicen que el trabajo tutorial en la universidad debe apoyarse en los siguientes criterios:

- La relación entre el profesor tutor y los estudiantes debe ser de ayuda para que éstos últimos puedan optimizar determinadas tareas académicas y/o personales.

- Cada estudiante es un ser único e irrepetible, lo que requiere del tutor aceptar su singularidad y el compromiso de su potenciación. Se establece así una relación de ayuda personalizada.

- La persona debe ser considerada en su globalidad para poder alcanzar el desarrollo armónico de todas sus potencialidades. La sociedad en general y el mercado profesional en particular exigen cada vez más ciertas habilidades que no obedecen estrictamente a conocimientos técnicos o aplicados. Incluso, se aprecia en el mundo laboral una clara tendencia a la valoración creciente de los aspectos personales frente a los aspectos meramente instructivos.

- La interdisciplinariedad es uno de los aspectos de la formación académica más aconsejable en el momento actual. La parcelación en que habitualmente se han transmitido los conocimientos impide que el estudiante se habitúe a reflexionar y analizar los problemas o situaciones desde

\footnotetext{
${ }^{61}$ LÓPEZ FRANCO Eloisa y OLIVEROS, Laura. La tutoría y la orientación en la universidad. Madrid: Revista española de orientación y psicopedagogía, Vol. 10, № 17, 1999, p. 86.

62 lbid.

${ }^{63}$ RODRÍGUEZ MORENO, María Luisa y GALLEGO, Sofía. El proyecto profesional, herramienta de intervención en la función tutorial universitaria. Madrid: Revista española de orientación y psicopedagogía, Vol. 10, № 17, 1999, p. 184.
} 
la perspectiva total de las diferentes materias, situación ésta que le merma objetividad y visión de conjunto.

- Las siguientes son algunos elementos básicos para desarrollar un plan de tutoría en la universidad:

- Seguimiento a las competencias, actividades y logros que se desean alcanzar

- Fortalezas y debilidades detectadas por el propio estudiante en su proceso de autoevaluación y en las evaluaciones realizadas por el profesor.

- Actividades para superar las debilidades y afianzar las fortalezas.

- Horario, frecuencia y tipo (individual o colectiva) de atención a los estudiantes

\section{ESTRUCTURA CURRICULAR FUNDAMENTADA EN COMPETENCIAS}

Podemos asumir el currículo como una dimensión de la educación escolarizada que comprende competencias, conocimientos, procesos, resultados y actividades formativas, en torno a centros de interés (problemas, casos, teorías, temas, etc.) para estudiantes y profesores, desde una óptica investigativa.

El diseño curricular alrededor de centros de interés abarca varios momentos. El momento, a diferencia de la etapa, no necesariamente sigue un orden secuencial tipo $1^{\circ}, 2^{\circ}, 3^{\circ}$, pues se puede avanzar, retroceder, moverse en diferentes direcciones. Dichos momentos pueden ser:

- Trabajo en equipo del profesorado

- Establecimiento de los criterios que orientan el currículo

- Tormenta de ideas para precisar los centros de interés

- Establecimiento de conexiones entre las disciplinas y los centros de interés

- Identificación de las competencias y los conocimientos a adquirir.

- Agrupamientos flexibles de las disciplinas

- Establecimiento de grados intermedios en el proceso de aprendizaje

- Determinación de los tiempos para desarrollar cada centro de interés y sus respectivos componentes.

- Evaluación continua y formativa del proceso de integración curricular 
- Consulta de experiencias curriculares innovadoras

- Recolección de toda la información posible sobre el proceso curricular.

- El currículo en la educación superior puede diseñarse tomando como centro de interés las competencias propias de cada profesión e integrándolas con los conocimientos y demás competencias (cognoscitivas, comunicativas, socioafectivas). Desde una visión muy universal, pueden tenerse en cuenta los "cuatro pilares de la educación" recomendados por la UNESCO ${ }^{64}$ :

- Aprender a conocer: concertar entre una cultura general suficientemente amplia y los conocimientos particulares de las diferentes disciplinas, en torno a problemas e interrogantes concretos. Esto requiere aprender a aprender, con el fin de aprovechar las posibilidades que ofrece la educación a lo largo de la vida.

- Aprender a hacer: adquirir no sólo una certificación profesional, sino más bien competencias que capaciten al individuo para hacer frente a gran número de situaciones previstas e imprevistas y a trabajar en equipo.

- Aprender a vivir juntos: realizar proyectos comunes y prepararse para asumir y resolver los conflictos, respetando los valores del pluralismo, el entendimiento mutuo y la paz, a través de la comprensión del otro y de las formas de interdependencia.

- Aprender a ser: actuar con creciente capacidad de autonomía, de juicio y responsabilidad personal, para que florezca en mejor forma la propia personalidad. Con tal fin, no subestimar ninguna posibilidad de cada individuo en su proceso educativo: competencias intelectuales (memorizar, razonar, comprender, etc.), comunicativas, afectivas, estéticas, físicas, entre otras.

Los gráficos 1 y 2 representan, respectivamente, el significado que poseen las competencias y el lugar que ocupan (centro de interés) en el diseño curricular:

\footnotetext{
${ }^{64}$ DELORS, Jacques. La educación encierra un tesoro. Madrid: Santillana, 1966, p. 95-108
} 


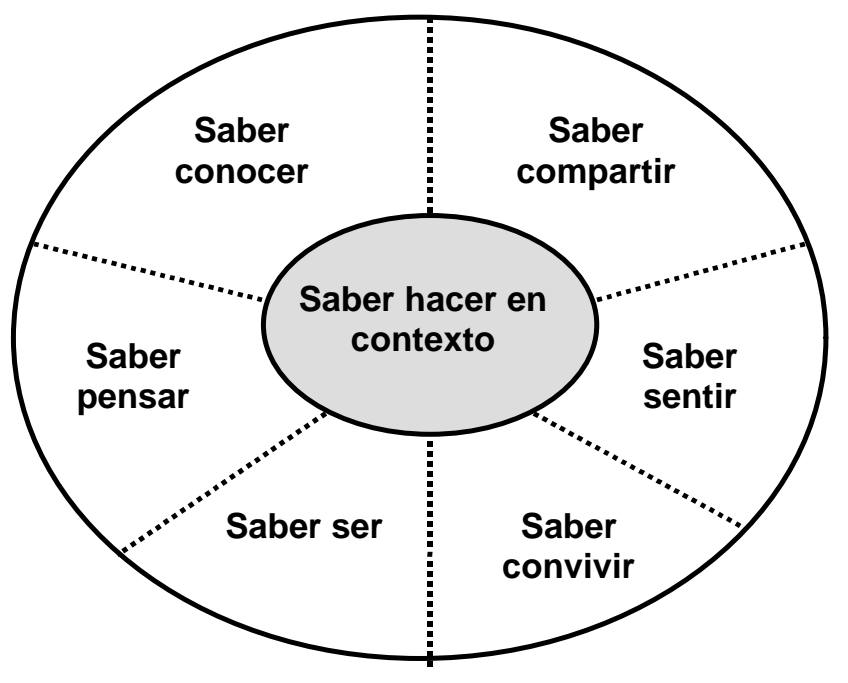

Como puede apreciarse en el gráfico 1, el saber hacer en contexto es el núcleo central de una competencia, en torno al cual gravitan los otros saberes: conocer, pensar, ser, convivir, sentir, compartir, etc. Por ejemplo, si un programa académico de ciencias de salud considera que sus egresados deben aprender a contribuir con la salud y seguridad de las personas y de sus ambientes (saber hacer), deben entonces aprender a analizar, interpretar y argumentar (pensar) los conocimientos relativos a la salud, la seguridad y el ambiente, y proponer alternativas de solución. Igualmente deben aprender a ser sensibles, a compartir con sus colegas (trabajo en equipo) y a comprometerse con las soluciones a la problemática planteada.

Gráfico 2: Estructura curricular con base en competencias

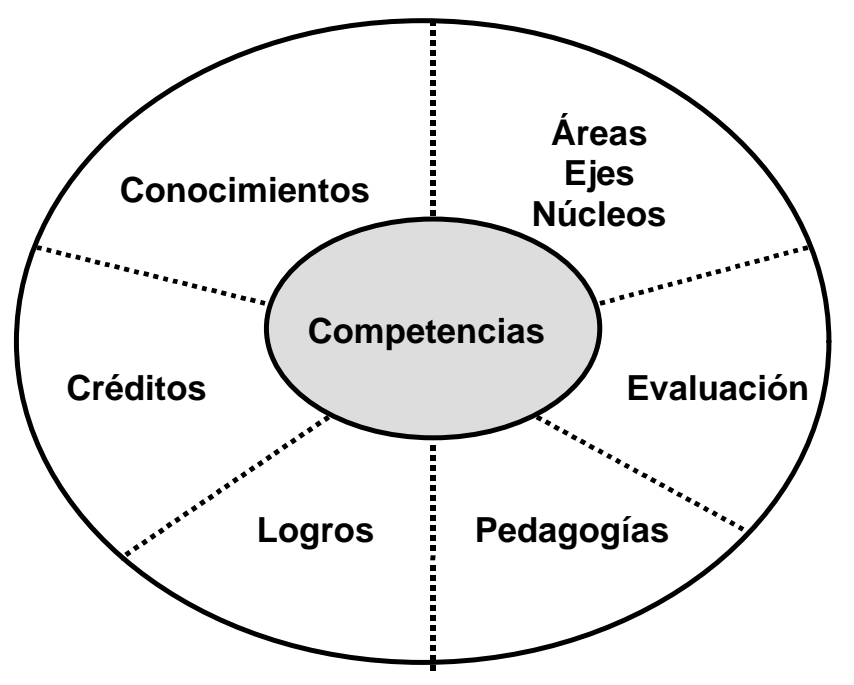

Acorde con el gráfico 2, el diseño curricular fundamentado en competencias tiene en cuenta el siguiente procedimiento, ya sea para el macrodiseño de una carrera, particularmente el plan de estudios, o el microdiseño de una actividad académica (clase, práctica, laboratorio, etc.): 
1. Identificar el conjunto de competencias (centros de interés) en sus diferentes niveles (áreas, cursos y actividades, en sus diversos grados de amplitud y complejidad) que han de adquirir los futuros profesionales (perfil profesional). Algunas de dichas competencias son intangibles, pues son parte del valor agregado que generan otras actividades académicas.

- Establecer los logros esperados (objetivos) y los criterios de desempeño (indicadores).

- Determinar los conocimientos requeridos (disciplinas) y su aplicación.

- Organizar los conocimientos (que se debe saber) en áreas, ejes temáticos, núcleos problémicos, componentes, etc., según el enfoque curricular y el correspondiente plan de estudios que se adopte.

- Determinar las estrategias pedagógicas y los medios didácticos (cómo enseñar y aprender), igual que las estrategias evaluativas (cómo y qué evidencias recoger sobre el desempeño del estudiante) apropiadas para obtener los logros esperados.

- Determinar los diversos cursos a desarrollar por parte de los profesores: contenidos, tiempos, pedagogías, estrategias evaluativas, tutorías, etc.

- Asignar los respetivos créditos a las áreas, los cursos, los períodos académicos y toda la carrera.

Este procedimiento se desarrolla avanzando y retrocediendo, en diálogo entre uno y otro punto. Por ejemplo, es posible que al establecer las estrategias evaluativas en determinado curso (punto 6) nos percatemos que las estrategias pedagógicas (punto 5) no son las más adecuadas, igual que los logros esperados y los indicadores de logro (punto 2), lo que implica revisar lo planteado con anterioridad. El trabajo en equipo es de sumo valor en este tipo de diseño curricular porque permite recoger las diferentes miradas sobre cada tópico y poder así construir consensos.

\subsection{Estructura de una competencia}

La estructura de una competencia la conforman tres componentes: acción, objeto y condición (que es parte del contexto en que se ejerce la competencia). En el diseño curricular con base en competencias, el proceso de construcción de dicha estructura se denomina identificación de competencias, en el cual es de suma importancia tener en cuenta ${ }^{65}$ :

- El desempeño profesional en el trabajo, puesto que él incluye los objetivos, los conocimientos, las habilidades y actitudes que una persona debe combinar y poner en acción en diferentes contextos laborales.

\footnotetext{
${ }^{65}$ IRIGOIN, María y VARGAS, Fernando. Competencia laboral. Manual de conceptos, métodos y aplicaciones en el sector salud. Montevideo: CINTERFOR, 2002, p. 79-80.
} 
- La realización de estudios o análisis ocupacionales a cargo de grupos de trabajo constituidos por personas provenientes de cuatro vertientes distintas: profesionales, especialistas, empleadores y metodólogos especializados en competencias.

Veamos algunos ejemplos de identificación de competencias:

\begin{tabular}{|lll|}
\hline \multicolumn{1}{|c|}{ ACCIÓN } & OBJETO & CONDICIÓN \\
\hline 1. Escribir & un texto & De 5 páginas \\
\hline 2. Pronunciar & un discurso & En la sala de clase \\
\hline 3. Producir y procesar & papel & según demanda nacional \\
\hline 4. Promover & la igualdad & para todas las personas \\
\hline 5. Recoger & información & sobre historia familiar \\
\hline 6. Diseñar y desarrollar & una clase & para primer semestre \\
\hline
\end{tabular}

En los ejemplos anteriores observamos la estructura de cada competencia, conformada por la acción (verbo) que debe ejecutarse, el objeto sobre el cual recae la acción y unas condiciones que hacen parte del contexto laboral. Esta estructura es válida para cualquier tipo de competencia (cognitiva, comunicativa, socioafectiva, laboral, etc.). Como dijimos anteriormente, una vez identificadas las competencias se procede a diseñar el resto del currículo en sus distintos componentes.

La primera competencia, "escribir un texto de 5 páginas", no es clara, pues el objeto y la condición son muy generales y ambiguos, ya que no especifican otros componentes importantes, tales como el tipo de texto, la redacción, la gramática, la ortografía y la presentación del escrito, elementos éstos que podrían servir como indicadores de logros. En consecuencia, evaluar el desempeño de un estudiante tal como está estructurada la mencionada competencia sería un acto superficial y confuso, no se sabría exactamente qué aprendió. Usted puede continuar con el análisis del resto de competencias presentadas en el ejemplo anterior. Es recomendable no recargar las competencias con demasiadas acciones y objetos. Pero si deben especificarse al máximo las condiciones.

\subsection{Estructura de un árbol de competencias}

Un árbol de competencias es una estructura conformada por macrocompetencias, de las cuales se derivan varias competencias con sus logros e indicadores de logros. Esta estructura, con sus respectivos conocimientos, refleja en forma integral la composición de una actividad académica compleja, o de una profesión en su totalidad. 


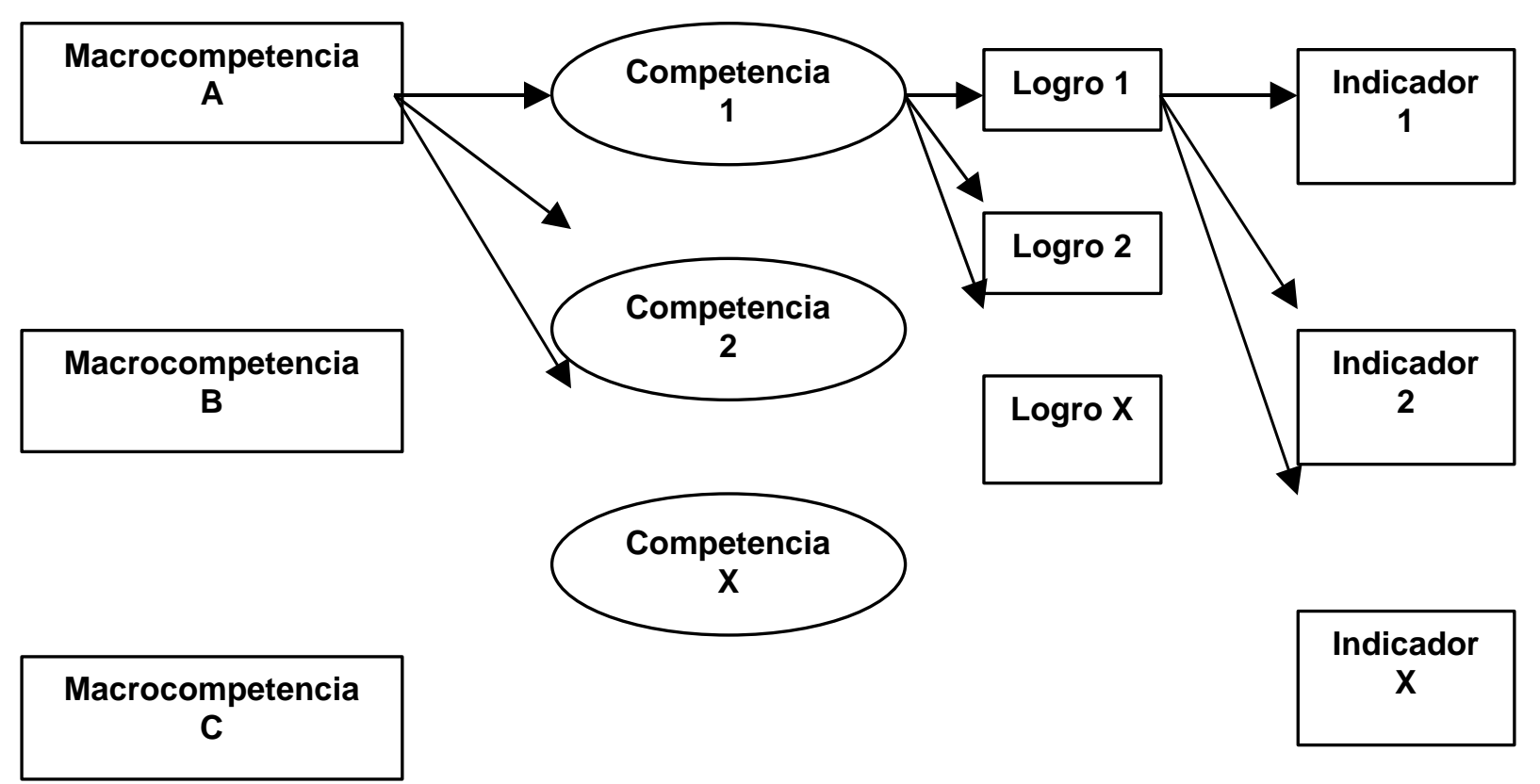

Veamos un ejemplo: un profesor que enseña diseño curricular propone el siguiente objetivo a sus estudiantes: aprender a diseñar un currículo con base en competencias para una profesión $X$. Los estudiantes diseñan la primera parte que aparece enseguida. Usted puede continuar con el resto.

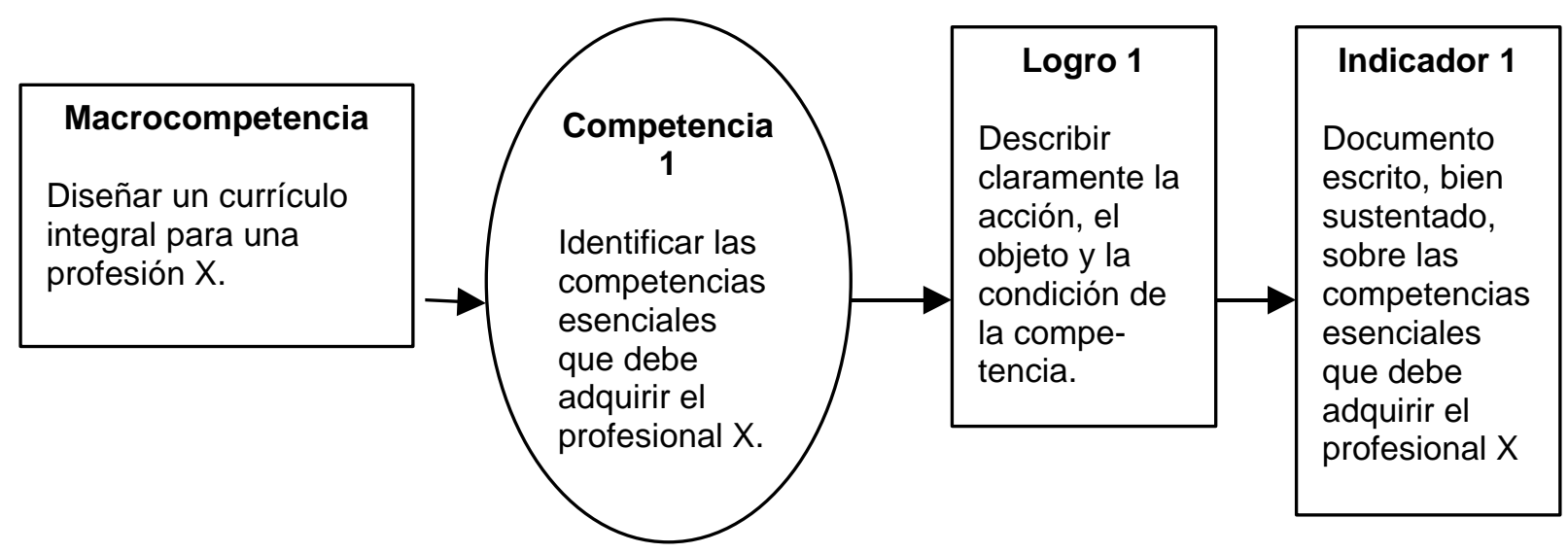

En igual forma se procede con cada una de las macrocompetencias que integran una profesión, desagregadas en períodos académicos, cursos, asignaturas, ejes temáticos, núcleos problémicos, etc. Con base en un árbol de competencias se puede diseñar el trabajo interdisciplinario, la tutoría a los estudiantes, la formación investigativa, las prácticas de laboratorios, de campo y de entrenamiento profesional. 


\section{BIBLIOGRAFÍA}

BLYTHE, Tina, et al. La enseñanza para la comprensión. Buenos Aires: Paidós, 1999.

BUNK, G. P. La transmisión de las competencias en la formación y perfeccionamiento profesionales en la RFA. Revista CEDEFOP, N 1, 1994.

CAPPER, Phillip. "La competencia en contextos laborales complejos". En: ARGÜELLES, Antonio y GONCZI, Andrew. Educación y capacitación basada en normas de competencias: una perspectiva internacional. México: Limusa, 2001.

CONSEJO NACIONAL DE CERTIFICACIÓN. www.cinterfor.org.uy

COOPER, Robert $\mathrm{K}$ y SAWAF, Ayman. La inteligencia emocional aplicada al liderazgo y a las organizaciones. Bogota: Norma, 1998.

DELORS, Jacques. La educación encierra un tesoro. Madrid: Santillana, 1966.

DEWEY, John. Cómo pensamos: Nueva exposición de la relación entre pensamiento reflexivo y proceso educativo. Barcelona: Paidós, 1989.

HERNÁNDEZ, Carlos Augusto, et al. Exámenes de Estado: Una propuesta de evaluación por competencias. Bogotá: Javegraf, 1998.

IRIGOIN, María y VARGAS, Fernando. Competencia laboral. Manual de conceptos, métodos y aplicaciones en el sector salud. Montevideo: CINTERFOR, 2002.

GARDNER, Howard. Inteligencias múltiples. Barcelona: Paidós, 1995.

GOLEMAN, Daniel. La inteligencia emocional. Buenos Aires: Javier Vergara, 1999.

GONCZI, Andrew. "Problemas asociados con la implementación de la educación basada en la competencia: de lo atomístico a lo holístico". En: CINTERFORT/OIT. Formación basada en competencia laboral. 1997.

GONCZI, Andrew. "Análisis de las tendencias internacionales y de los avances en educación y capacitación laboral basadas en normas de competencias". En: ARGÜELLES, Antonio y GONCZI, Andrew. Educación y capacitación basada en normas de competencias: una perspectiva internacional. México: Limusa, 2001. 
GONCZI, Andrew y ATHANASOU, James. Instrumentación de la educación basada en competencias. Perspectiva de la teoría y la práctica en Australia. Limusa, 1996.

HARRIS, R, et al. Competency-based education: Between a rock and whirlpool. McMillan: Melbourne. En: ARGÜELLES, Antonio y GONCZI, Andrew. Educación y capacitación basada en normas de competencias: una perspectiva internacional. México: Limusa, 2001.

INSTITUTO NACIONAL PARA EL EMPLEO. Metodología para la ordenación de la formación profesional ocupacional. Subdirección general de gestión de formación ocupacional. Madrid, 1995.

LÓPEZ FRANCO Eloisa y OLIVEROS, Laura. La tutoría y la orientación en la universidad. Madrid: Revista española de orientación y psicopedagogía, Vol. 10, № 17, 1999.

MACDONALD, Rod, et al. "Nuevas perspectivas sobre la evaluación". UNESCO, París, 1995. En: CINTERFOR-OIT. Competencias laborales en la formación profesional. Boletín Técnico Interamericano de Formación Profesional. № 149, mayo-agosto de 2000.

MASSEILOT, Héctor. "Competencias laborales y procesos de certificación ocupacional". En: CINTERFOROIT. Competencias laborales en la formación profesional. Boletín Técnico Interamericano de Formación Profesional. № 149, mayo-agosto de 2000.

MAURINO, D. E. et al. Beyond aviation: Human factors. Avebury: Aldershot, 1995. En: CAPPER, Phillip. "La competencia en contextos laborales complejos". En: ARGÜELLES, Antonio y GONCZI, Andrew. Educación y capacitación basada en normas de competencias: una perspectiva internacional. México: Limusa, 2001.

MERTENS, Leonard. Competencia Laboral: Sistemas, surgimiento y modelos. CINTERFOR. Montevideo, 1997.

MINISTERIO DE EDUCACIÓN NACIONAL DE COLOMBIA. Decreto 808 del 25 de abril de 2002.

MORIN, Edgar. Los siete saberes necesarios para la educación del futuro. Bogotá: Imprenta Nacional, 2000.

ORGANIZACIÓN INTERNACIONAL DEL TRABAJO. Formación profesional. Glosario de términos escogidos. Ginebra, 1993.

PÉREZ ABRIL, Mauricio. "Competencia textual, competencia pragmática y competencia argumentativa. Ejes de la evaluación de producción de textos". En: Evaluación de Competencias básicas. Bogotá: Universidad Nacional, 1999.

PIAGET, Jean. La epistemología de las relaciones interdisciplinarias. En: L. APOSTEL, G. BERGERR, A. BRIGGS Y G. MICHAUD. Interdisciplinariedad. Problemas de la enseñanza y de la investigación en 
la Universidades. México: Asociación Nacional de Universidades e Institutos de Enseñanza Superior, 1979.

POSADA ÁLVAREZ, Rodolfo. La investigación en el aula: Una alternativa para el trabajo docente. Santa Marta: Universidad del Magdalena, 1997.

RODRíGUEZ MORENO, María Luisa y GALLEGO, Sofía. El proyecto profesional, herramienta de intervención en la función tutorial universitaria. Madrid: Revista española de orientación y psicopedagogía, Vol. 10, № 17, 1999.

SANTOS GUERRA, Miguel Ángel. Evaluar es comprender. Buenos Aires: Magisterio Río de la Plata, 1998.

SCHON, Donald A. La formación de profesionales reflexivos. Barcelona: Paidós, 1992.

SENGE, Peter M. La quinta disciplina. El arte y la práctica de la organización abierta al aprendizaje. Barcelona: Granica, 1996.

SLADOGNA, Mónica G. "Una mirada a la construcción de las competencias desde el sistema educativo. La experiencia Argentina". En: CINTERFOR-OIT. Competencias laborales en la formación profesional. Boletín Técnico Interamericano de Formación Profesional. № 149, mayo-agosto de 2000.

STEVENSON J. "The political colonization of the cognitive construction of competence". En: MISKO, Josie y ROBINSON, Chris. La capacitación basada en normas de competencia en Australia. En: ARGÜELLES, Antonio y GONCZI, Andrew. Educación y capacitación basada en normas de competencias: una perspectiva internacional. México: Limusa, 2001.

TORRES SANTOME, Jurjo. Globalización e interdisciplinariedad: El curriculum integrado. Madrid: Morata, 1996.

UNESCO. "Declaración mundial sobre la educación superior en el siglo XXI: Visión y acción". Conferencia mundial sobre la educación superior. París, octubre de 1998. En: ASOCIACIÓN COLOMBIANA DE UNIVERSIDADES. Cuadernos Ascun. Bogotá: Ascun, 1999, № 7.

VARGAS ZÚÑIGA, Fernando. "De las virtudes laborales a las competencias claves: un nuevo concepto para antiguas demandas". En: CINTERFOR-OIT. Competencias laborales en la formación profesional. Boletín Técnico Interamericano de Formación Profesional. № 149, mayo-agosto de 2000.

VARGAS ZUÑIGA, Fernando. Competencia en la formación y competencia en la gestión del talento humano. Convergencias y desafíos. CINTERFOR/OIT, www.cinterfor.org.uy , 2002. 


\title{
Contactar
}

Revista lberoamericana de Educación

\author{
Principal OEI
}

